\title{
IMPLEMENTAÇÃO DE UM BIODIGESTOR PARA SÃO FRANCISCO DE SALES E REGIÃO
}

\section{ARTIGO ORIGINAL}

SILVA, João Divino dos Santos ${ }^{1}$

BARBOSA, Fernando Aparecido Oliveira ${ }^{2}$

MORAES, Janine Alves ${ }^{3}$

BORGES, Tainara Letícia Silva ${ }^{4}$

SILVA, Otoniel Gomes da ${ }^{5}$

SILVA, João Divino dos Santos. Et al. Implementação de um biodigestor para São Francisco De Sales e região. Revista Científica Multidisciplinar Núcleo do Conhecimento. Ano 04, Ed. 12, Vol. 03, pp. 143-163. Dezembro de 2019. ISSN: 24480959, Link de acesso: https://www.nucleodoconhecimento.com.br/engenhariaambiental/implementacao-de-um-biodigestor

\section{RESUMO}

O presente artigo aborda a implantação de um biodigestor com tecnologia alemã, como solução para o tratamento de resíduos sólidos orgânicos em um proposto Plano Microrregional de Resíduos Sólidos (PLMRS). Este plano engloba cerca de 14

\footnotetext{
${ }^{1}$ Mestrando em Ciências Ambientais, Especialista em Engenharia Sanitária, graduado em Engenharia Civil.

${ }^{2}$ Graduando em Engenharia Civil.

${ }^{3}$ Graduando em Engenharia Civil.

${ }^{4}$ Graduando em Engenharia Civil.

${ }^{5}$ Graduando em Engenharia Civil.
} 
municípios do triângulo mineiro, onde São Francisco de Sales será o município que, supostamente, terá em seu território a instalação deste biodigestor para sua própria demanda de material orgânico, e dos demais municípios pertencentes ao plano. Consequentemente, ao se tratar dos resíduos orgânicos de forma adequada, além de reduzir o volume de resíduos destinados a "lixões" e aterros sanitários, resultará em subprodutos como o biogás e o biofertilizante pelo processo de biogasificação, dos quais poderão ser comercializados no mercado local. Com base nos dados gravimétricos do Brasil apresentados pelo Plano Nacional dos Resíduos Sólidos, comprovou-se que a proporção de material orgânico também se aplica a cidade de São Francisco de Sales, utilizando o método de quarteamento no aterro sanitário local. Ao se obter registros da estimativa populacional dos municípios pertencentes ao suposto PLMRS pelo Instituto Brasileiro de Geografia e Estatística (IBGE), além de dados da Associação Brasileira de Empresas de Limpeza Pública e Resíduos Especiais (ABRELPE), informando a quantidade de resíduos sólidos produzidos por cada habitante, foi possível estipular a produção total de resíduos orgânicos e estimar um investimento para implementação de um biodigestor com a tecnologia alemã, utilizando como modelo o da empresa Refood, construído na cidade de Marl, do estado de Renânia, na Alemanha.

Palavras-chave: Biodigestor, resíduos sólidos orgânicos, biogasificação, biogás, biofertilizante.

\section{INTRODUÇÃO}

Há uma carência significativa no plano diretor na grande maioria dos municípios, no que se refere a falta de projetos e estratégias para a destinação, reciclagem e, se possível, reuso dos RSU gerados pela população. Como consequência, são visíveis os impactos ambientais causados pelo descarte e armazenamento inadequado desses resíduos.

Tendo em vista a necessidade de buscar soluções para reduzir os impactos e danos causados pelo descarte de resíduos no meio ambiente, avalia-se que a implantação 
de um biodigestor seria uma opção viável para tratar dos RSO, que compõem grande parte dos RSU gerados pela população. Essa central, por sua vez, permite a reabilitação de grande parte das zonas degradadas e faz com que a reciclagem das matérias orgânicas presentes nos RSU, surja como resposta às preocupações voltadas aos recursos não renováveis.

O presente trabalho busca desenvolver um estudo sobre o que são biodigestores, alinhando preocupações com o meio ambiente, custo/benefício da implantação, qualidade do produto gerado ao final do processo, onde e como utilizá-lo. Ao final, estimar o custo de implantação de um biodigestor com tecnologia alemã no município de São Francisco de Sales, situada no interior do estado de Minas Gerais, no Triângulo Mineiro. Essa instalação atenderá a um proposto PLMRS, envolvendo não somente a demanda de RSO gerados pela cidade de São Francisco de Sales, mas também a de outros municípios vizinhos, para que se tenha um maior volume de matéria orgânica a ser tratada e, consequentemente, uma maior produção de biogás e biofertilizante.

\section{REFERENCIAL TEÓRICO}

\subsection{RECICLAGEM}

De acordo com Lomasso et al. (2015), a ideia de reciclagem parte de inserir no processo produtivo, materiais que foram descartados por não serem mais úteis como matéria-prima na produção de novos bens, ou seja, a reciclagem é o processo de reaproveitamento de resíduos através de sua reinserção no ciclo produtivo, propondo inúmeros benefícios para a população da cidade e para o meio ambiente.

No Brasil, segundo Gouveia (2012), a produção de RSU vem apresentando um crescimento em todos os estados do país, em uma proporção de $7 \%$ ao ano, enquanto o crescimento populacional situa-se no patamar de $1 \%$ ao ano. Por isso, a coleta seletiva dos RSU e a separação realizada manualmente ou em usinas de triagem, são 
essenciais para a reciclagem, pois desta dependem todo o processo de transformação deste material para fabricação de novos produtos.

Em agosto de 2010, ocorreu a aprovação da Lei 12.305, que instituiu a Política Nacional de Resíduos Sólidos (PNRS), alterando a então vigente Lei 9.605 de fevereiro de 1998, onde no art. 54, declara-se o fim dos lixões em todos os municípios dentre o período de quatro anos após sua publicação, ou seja, até dia 02 de agosto de 2014 como meio para serviço operacionais de reciclagem.

Art. 54 - A disposição final ambientalmente adequada dos rejeitos, observado o disposto no $\S 1$ 으 do art. 9o, deverá ser implantada em até 4 (quatro) anos após a data de publicação desta Lei. (LEI № 12.305, de 2 de agosto de 2010)

No entanto, em 2015 foi proposto pela Câmara dos Deputados a aprovação do Projeto de Lei № 2.289, declarando a prorrogação do prazo para o fim dos lixões em todos os municípios até o dia 31 de julho de 2021 (BRASIL, 2015, p.2). O cumprimento dessa lei, se aprovada, será de suma importância para os municípios, uma vez que se trata do fim do método de reciclagem mais prejudicial à natureza, pois em consequência da degradação dos resíduos com presença de material orgânico, produz um líquido escuro denominado chorume, rico em elementos que podem contaminar o ar, o solo e os lençóis freáticos (VILELA et al., 2015, p.6).

\subsection{RESÍDUOS SÓLIDOS}

O termo "resíduos sólidos" segundo Pichtel (2005), apud Deus et al. (2015), é definido como um material sólido com descarte barato em relação ao seu próprio uso, devido a este proporcionar valores econômicos negativos para aqueles que o descartam. Quando se trata dos parâmetros atuais que envolvem o valor econômico dos resíduos sólidos, a PNRS os descreve na Lei 12.305/10 como:

XVI - resíduos sólidos: material, substância, objeto ou bem descartado resultante de atividades humanas em sociedade, a cuja destinação final se procede, se propõe proceder ou se está obrigado a proceder, nos estados sólido ou semissólido, bem como gases contidos em recipientes 
e líquidos cujas particularidades tornem inviável o seu lançamento na rede pública de esgotos ou em corpos d'água, ou exijam para isso soluções técnica ou economicamente inviáveis em face da melhor tecnologia disponível. (LEI № 12.305, de 2 de agosto de 2010)

Os resíduos sólidos também podem ser caracterizados segundo sua origem, conforme Tchobanoglous e Kreith (2002), apud Deus et al. (2015) em:

- Residenciais;

- Comerciais;

- Institucionais;

- Industriais;

- Agrícolas.

- Construção e demolição;

- Serviços municipais;

- Centrais de tratamento;

Para os efeitos da Norma NBR 10004:04, os resíduos descartados são classificados em:

a) Resíduos classe I - Perigosos;

b) Resíduos classe II - Não perigosos;

- Resíduos classe II A - Não inertes.

- Resíduos classe II B - Inertes.

Esta Norma também propõe um conjunto de análise para classificação do tipo de resíduo, do qual se pertence a um dos quatro grupos citados acima em forma de fluxograma, apresentado na Figura 01 abaixo. Essa série de questões para definição do tipo de resíduo, depende da sua origem, se é um resíduo perigoso de fontes específicas (Anexo B) ou não específicas (Anexo A), de suas características e se possui constituintes que são solubilizados em concentrações superiores aos padrões para o ensaio de solubilização (Anexo G) (NBR 10004:04, p.6). 
Figura 01: Caracterização e classificação de resíduos.

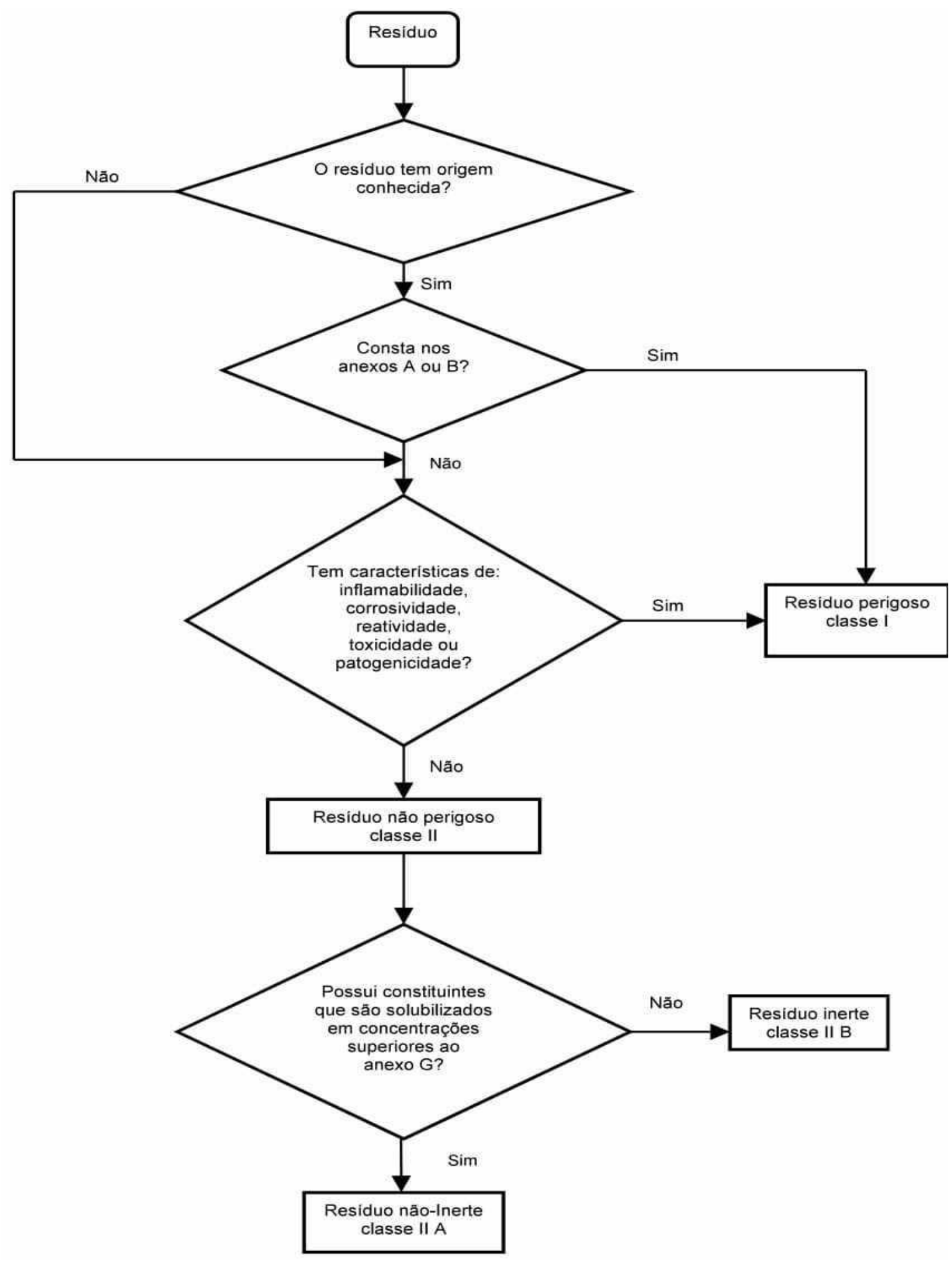

(NBR10004:04)

RC: 42322

Disponível em: https://www.nucleodoconhecimento.com.br/engenharia-ambiental/implementacaode-um-biodigestor 


\subsubsection{RESÍDUOS SÓLIDOS ORGÂNICOS (RSO)}

Resíduo sólido orgânico é todo material descartado como lixo que deriva de um ser vivo, ou seja, trata-se de um material que tem a matéria orgânica como seu componente biológico, que inclui folhas, restos de carnes e ossos, papéis, restos de alimentos, madeira etc. (BOJADSEN, 1997, apud ALMEIDA et al., 2013, p.28).

Segundo Almeida et al. (2013), esse tipo de resíduo é considerado poluente ao meio ambiente, devido que, além de ser altamente malcheiroso, proporciona durante seu processo de decomposição um ambiente favorável para o desenvolvimento de microrganismos com grandes agentes causadores de doenças. $O$ autor também descreve que através de projetos para o saneamento básico municipal, é possível manter o controle do descarte correto dos RSO, onde boa parte é composta de rejeitos gerados pelo corpo humano como fezes e urina, evitando-se a proliferação de vermes, bactérias, fungos e vírus, e consequentemente, reduzindo o nível de possível transmissão de doenças geradas por esse material.

Por outro lado, o potencial poluidor produzido por esse material orgânico, com tratamento adequado, pode ser usado para diversos fins como adubos e fertilizantes a partir da compostagem e vermicompostagem, ou pelo processo de biogasificação para a produção de certos combustíveis como biogás, devido à degradação dos RSO gerarem um alto índice de metano (JAMES, 1992, apud ALMEIDA et al., 2013, p.28).

\subsection{BIODIGESTOR}

No Brasil, segundo Kunz e Oliveira (2006), apud Rocha (2016), os primeiros modelos de biodigestores utilizados no Brasil foram provenientes da China, Índia e Canadá. De acordo com Odelmo Leão (2012), ocorreu a implantação do sistema de produção de Biogás em Uberlândia/MG, sendo a segunda no estado de Minas Gerais e a quinta no país a adotar essa forma de tratamento de resíduos, fornecendo 1,4 megawatts de energia elétrica à Companhia Energética do Estado de Minas Gerais (CEMIG). 
Com relação ao princípio de funcionamento de um biodigestor, apresentaremos o modelo simplificado na Figura 05 descrito em um vídeo no canal "GLEYSSON" da plataforma do Youtube pelo professor Me. Gleysson Bezerra Machado, Engenheiro Químico formado pela Universidade de Ciências Aplicadas de Frankfurt/M na Alemanha, com especialização e experiência em Tecnologias para geração de Energia e Engenharia Ambiental.

Figura 05: Modelo do princípio de funcionamento de um biodigestor, GLEYSSON, 2013.

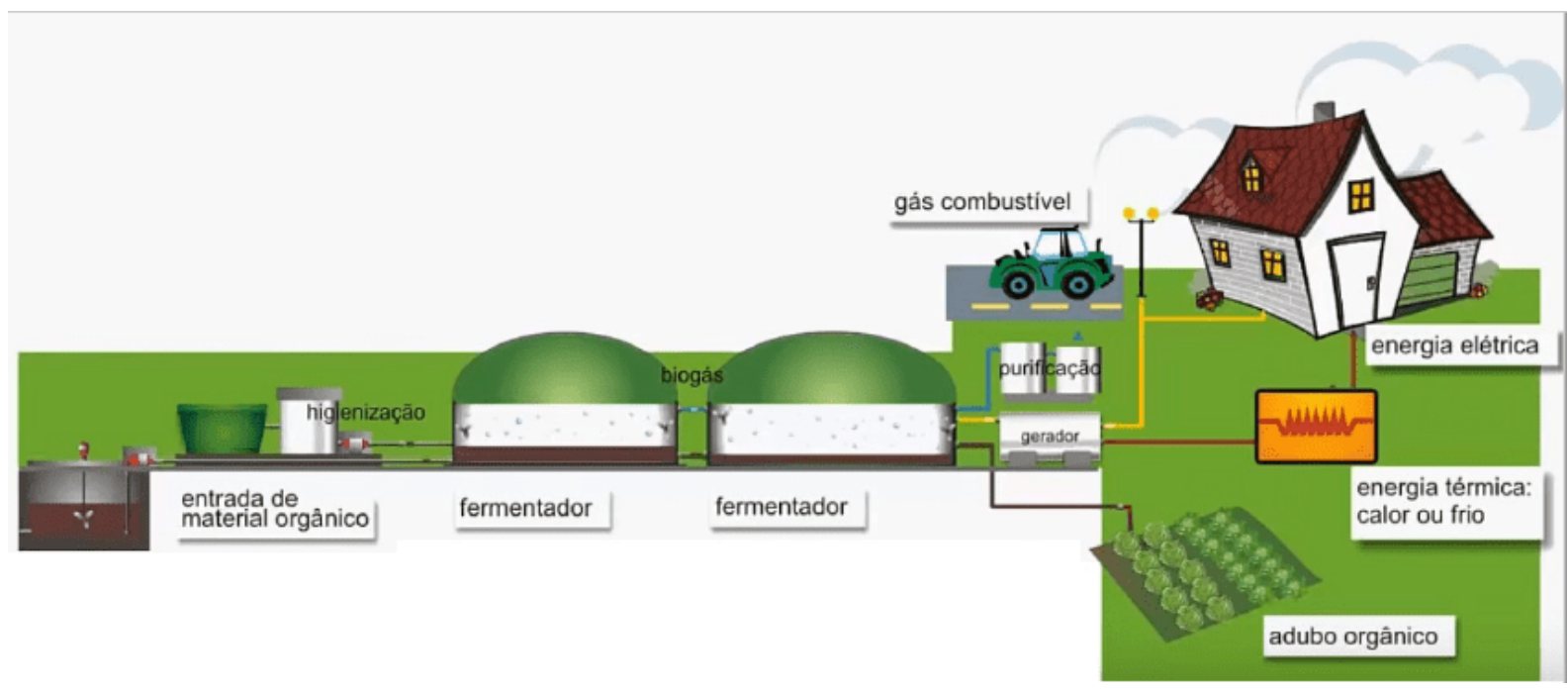

Fonte: Captura de tela do vídeo aula "Resíduos Sólidos - Biodigestor - princípio de funcionamento, classificação e viabilidade econômica" - Gleysson, Youtube, 2013.

Segundo Gleysson (2013), antes da entrada do material orgânico no fermentador, os RSO devem ser misturados e colocados em um local de armazenagem juntamente com o material higienizado, no caso de haver restos de animais presente. É possível ser acrescentado como substrato para produção de biogás e fertilizante, as fezes de animais, plantas energéticas e diferentes tipos de biomassa, dependendo da tecnologia utilizada no fermentador (Gleysson, 2012, 1m50s-2m38s). A escolha dessa tecnologia poderá variar conforme a origem do material orgânico que venha ser tratado, podendo ser proveniente de resíduos sólidos orgânicos urbanos, industriais, de agronegócios, e até mesmo de efluente municipais e industriais, ou de lodo de 
estações de tratamento de esgoto (ENERGIA E MEIO AMBIENTE, 2014, 2m40s$4 \mathrm{~m} 07 \mathrm{~s})$.

Dentro do fermentador ocorre a degradação anaeróbica da matéria orgânica, onde com o auxílio interno de um misturador para trazer homogeneidade à mistura, é possível manter um controle de ph e temperatura, para que as bactérias possam realizar esse processo de uma forma mais eficiente (GLEYSSON, 2012, 5m27s$5 \mathrm{~m} 51 \mathrm{~s})$

Dependendo do tipo e da variação de matéria orgânica utilizada para a produção do biogás e do biofertilizante, resultará em sua concentração e qualidade devida destes subprodutos. Isso ocorre, pois cada substrato inserido apresenta diferentes propriedades químicas, o que afeta diretamente na produção final, necessitando-se de uma análise química apropriada para se estabelecer quais os tipos de substratos que alavancam o potencial de geração deste sistema, obtendo um subproduto ideal (GLEYSSON, 2013, 3m40s-7m38s).

Após o processo de degradação, um dos produtos resultantes será o biogás. Este subproduto poderá passar por um processo de purificação, onde ocorre a separação do gás carbônico $\left(\mathrm{CO}_{2}\right)$, a fim de se obter apenas o gás metano $\left(\mathrm{CH}_{4}\right)$ para comercialização como gás combustível (GLEYSSON, 2013,10m08s-10m43s). Também pode-se utilizar o biogás e queimá-lo em um gerador de energia, podendo ser consumida para diversos fins (GLEYSSON, 2013, 9m02s-9m22s). É necessário que haja um trocador de calor para o resfriamento do gerador, podendo ser reaproveitado esta energia térmica como fonte de aquecimento de casas, de processos industriais e também para regular a temperatura interna dos próprios fermentadores da central (GLEYSSON, 2013, 9m24s-10m:00s).

O biofertilizante é o material líquido resultante da degradação anaeróbica alojado no fundo do fermentador, que pode ser utilizado em campos da agricultura como adubo orgânico, mas somente com a permissão do órgão estadual responsável pelo meio ambiente, após ser feita uma análise em sua composição química, em razão de se 
evitar posteriormente casos de contaminação do solo e danos à saúde humana ou animal (GLEYSSON, 2013).

\subsubsection{BIOGASIFICAÇÃO}

A biogasificação, também podendo ser definida como metanização ou digestão anaeróbica, é um dos tipos de tratamento dos RSO para produção de biogás, através da decomposição da matéria orgânica por bactérias que sobrevivem na ausência de oxigênio. Além da produção do biogás que é formado de cerca de $50 \%$ a $60 \%$ de metano para geração de energia elétrica ou como fonte de combustível, o resto do material orgânico resultante desse processo pode ser tratado aerobiamente para produção de adubo orgânico (MOTA et al., 2009).

Segundo Patil et al. (2011), apud Colombaroli (2015), o tratamento dos RSO por biogasificação é dividido em quatro etapas, conforme a ação de diferentes bactérias durante o processo: Hidrólise, Acidogênese, Acetogênese e Metanogênese.

A hidrólise é a primeira etapa da digestão anaeróbica, onde se origina-se as moléculas orgânicas solúveis como ácidos graxos, aminoácidos e açúcares, através da quebra das moléculas de carboidratos, proteínas e lipídios. A segunda etapa consiste na acidogênese, que é a continuação da quebra de moléculas menores por bactérias fermentativas, produzindo amônia, dióxido de carbono e $\mathrm{H}_{2} \mathrm{~S}$ como subprodutos. Em seguida, na acetogênese ocorre a produção de dióxido de carbono, ácido acético e hidrogênio, devido a digestão do material produzido na fase da acidogênese. $\mathrm{Na}$ metanogênese, última etapa da biogasificação, ocorre a transformação do ácido acético, do hidrogênio e do gás carbônico em metano, dióxido de carbono e água (GUNNERSON, 1986, apud ALMEIDA et al., 2013, p.32).

De acordo com o fluxograma apresentado pela Figura 02 abaixo, é possível visualizar o processo de biogasificação. 
Figura 02: Etapas do processo de biogasificação.

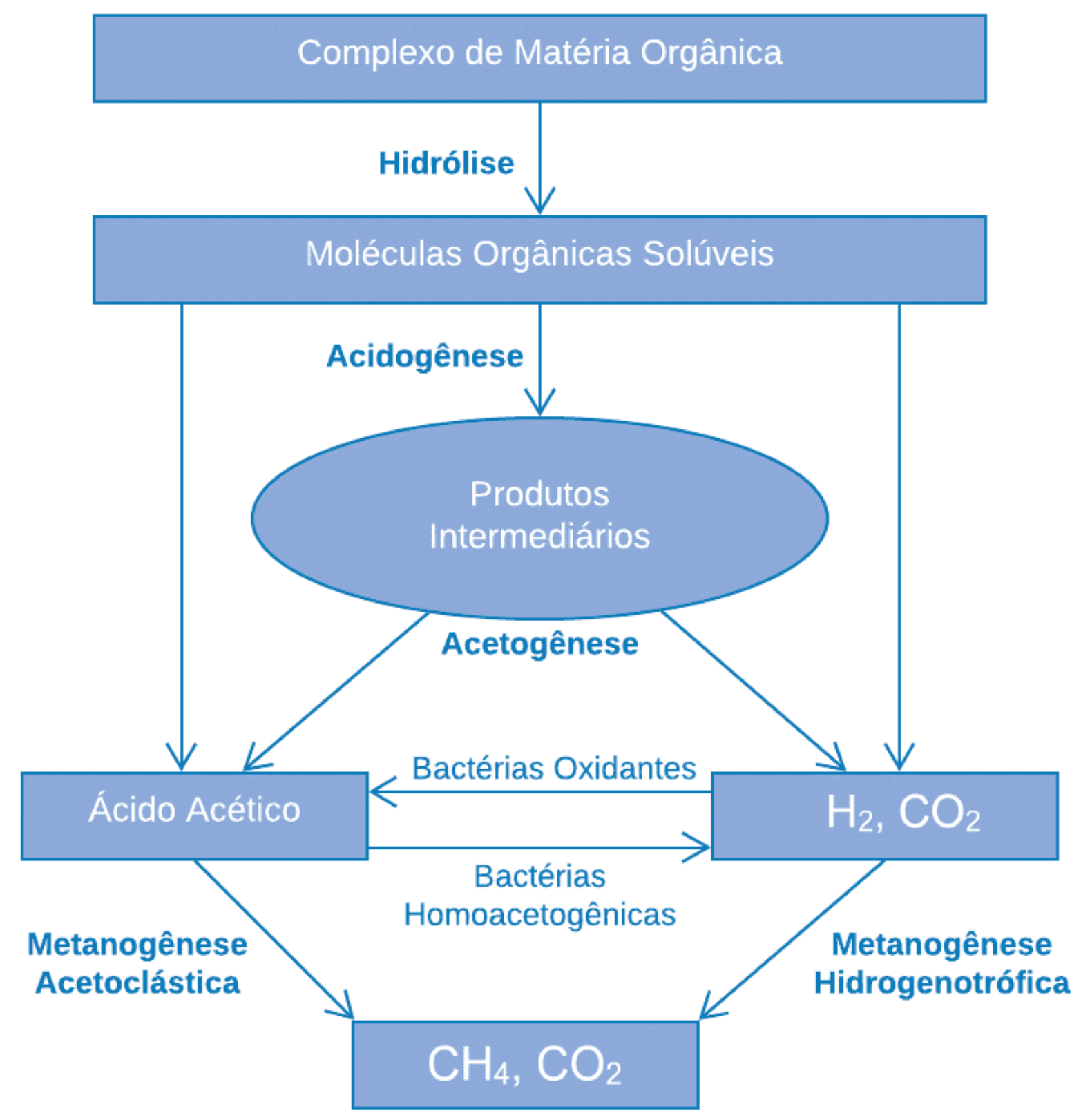

(PATIL et al. 2011, apud COLOMBAROLI, 2015)

\section{METODOLOGIA}

O procedimento de pesquisa utilizado para analisar a produção de RSO em São Francisco de Sales e região, foi realizada por meio documental e in loco. Para a cidade em si, foram realizadas visitas ao aterro sanitário local e um estudo gravimétrico da $\mathrm{RC}: 42322$

Disponível em: https://www.nucleodoconhecimento.com.br/engenharia-ambiental/implementacaode-um-biodigestor 
produção de RSU e, para os municípios vizinhos, a coleta de dados foi obtida a partir de informações fornecidos pelo PLNRS, além de dados publicados pelo IBGE e pela ABRELPE.

\subsection{PLANO DE TRATAMENTO DOS RSO}

Em função da Lei 12.305/10, promovemos a implantação de um PLMRS, envolvendo possíveis 14 municípios do estado de Minas Gerais situados a um raio de $100 \mathrm{~km}$ de distância, considerando a instalação do biodigestor no município de São Francisco de Sales como ponto central desta área abrangida. Com uma devida análise de viabilidade econômica mais precisa, municípios mineiros vizinhos, até mesmo dos estados de Goiás e São Paulo, poderão levar seus RSO para o tratamento após um acordo com os órgãos estaduais de licenciamento ambiental, além da aprovação dos responsáveis pela central de tratamento, no caso o biodigestor, se será ou não possível, comportar este acréscimo de material orgânico a se tratar.

Através da importação das malhas municipais do estado de Minas Gerais, fornecidas pelo site do IBGE para o software Google Earth Pro, foi possível visualizar as delimitações municipais que abrangem a área do PLMRS proposto. Conforme abaixo, se encontra na Tabela 01 e na Figura 03, os municípios escolhidos e suas respectivas localizações:

Tabela 1: Municípios pertencentes ao proposto PMRS

\begin{tabular}{|l|l|l|l|}
\hline № & CIDADE & № & CIDADE \\
\hline $\mathbf{1}$ & $\begin{array}{l}\text { São Francisco de } \\
\text { Sales }\end{array}$ & 8 & Frutal \\
\hline $\mathbf{2}$ & Iturama & 9 & Comendador Gomes \\
\hline $\mathbf{3}$ & Limeira do Oeste & 10 & Prata \\
\hline $\mathbf{4}$ & Carneirinho & 11 & Campina Verde \\
\hline $\mathbf{5}$ & União de Minas & 12 & Ituiutaba \\
\hline $\mathbf{6}$ & Itapagipe & 13 & Gurinhatã \\
\hline
\end{tabular}

Disponível em: https://www.nucleodoconhecimento.com.br/engenharia-ambiental/implementacaode-um-biodigestor 
7 Fronteira

\section{Santa Vitória}

Fonte: Autoria Própria.

Figura 03: Localização dos municípios pertencentes ao proposto PLMRS.

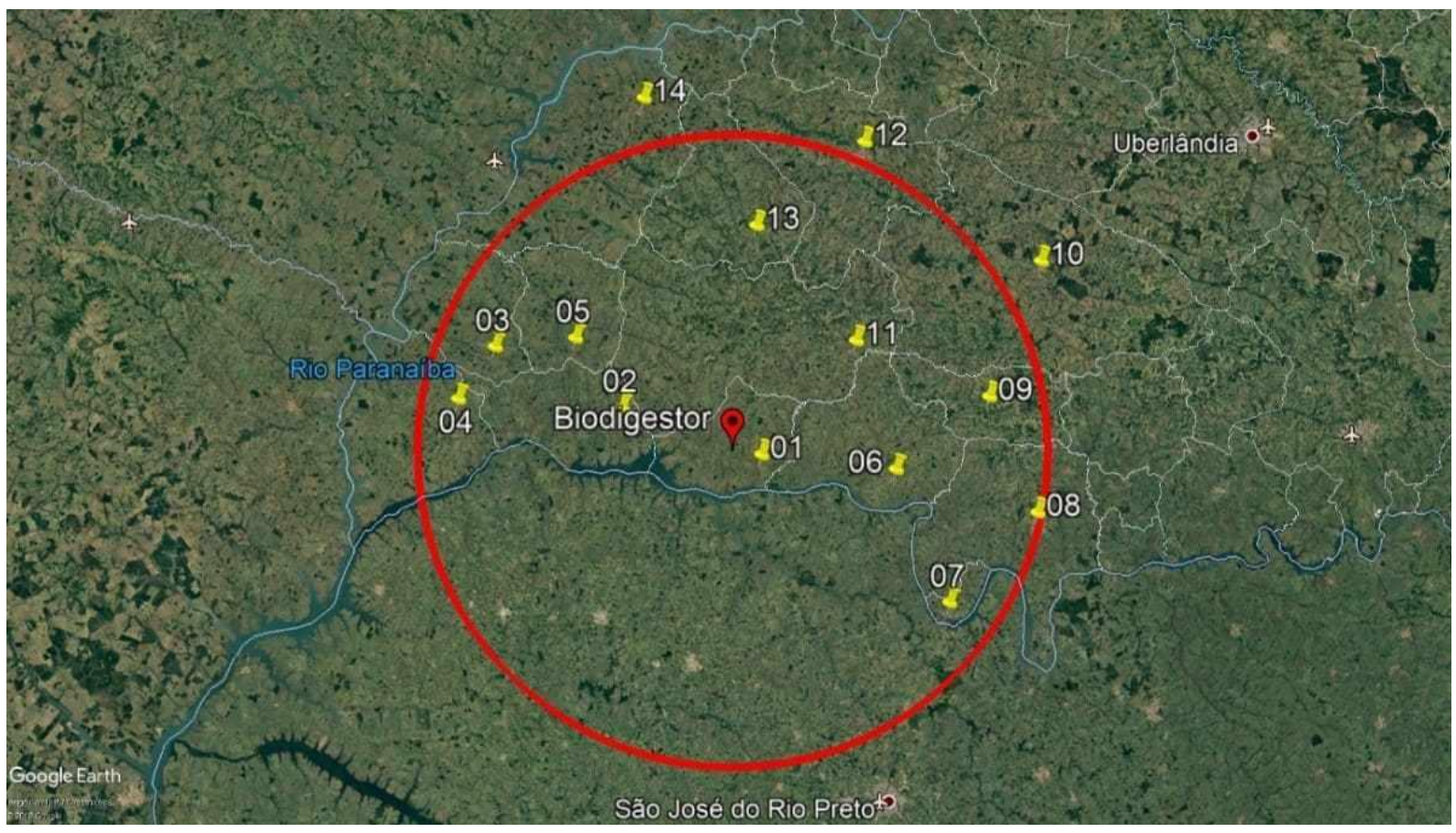

Fonte: Google Earth Pro com superposição do arquivo Minas Gerais-Malha Municipal.shp, IBGE/2018.

De acordo com a Figura 03, consideramos os municípios pertencentes a este PLMRS, os quais seu distrito-sede se localiza dentro da região delimitada em vermelho ou próxima a ela, podendo futuramente, após um estudo de viabilidade econômica mais amplo, adequar outros municípios mineiros ao plano.

Neste plano, delimitamos para a microrregião, como conjunto de municípios pertencentes somente ao estado mineiro, para evitar conflitos burocráticos com as diretrizes de diferentes órgãos responsáveis pelo licenciamento ambiental do estado. No entanto, os órgãos para licenciamento ambiental CETESB e SECIMA, respectivamente dos estados de São Paulo e Goiás, se desejarem, poderiam entrar em um acordo com a SEMAD, órgão responsável para licenciamento ambiental no

Disponível em: https://www.nucleodoconhecimento.com.br/engenharia-ambiental/implementacaode-um-biodigestor 
estado de Minas Gerais, e adotar este mesmo plano para municípios vizinhos à central de tratamento dos RSO, neste caso o Biodigestor no município de São Francisco de Sales.

Cada um dos 14 municípios pertencentes ao PLMRS, estariam responsáveis pela implantação local de uma usina de triagem, para que dos produtos provenientes da coleta seletiva, fossem separados somente os RSO para o transporte até a central de tratamento. Os demais materiais recicláveis seriam vendidos para indústrias como matéria prima de produção, e aqueles que não são classificados como RSO ou material reaproveitável, serão enviados para aterros sanitários.

\subsection{PLANO MICRORREGIONAL DE RESÍDUOS SÓLIDOS (PLMRS)}

De acordo com a Lei 12.305/10, em relação aos planos estipulados como instrumentos da PNRS, é possível organizar em uma hierarquia o devido funcionamento do PLMRS proposto, conforme o fluxograma da Figura 04 abaixo:

Figura 04: Hierarquia do proposto PLMRS como instrumento da PNRS.

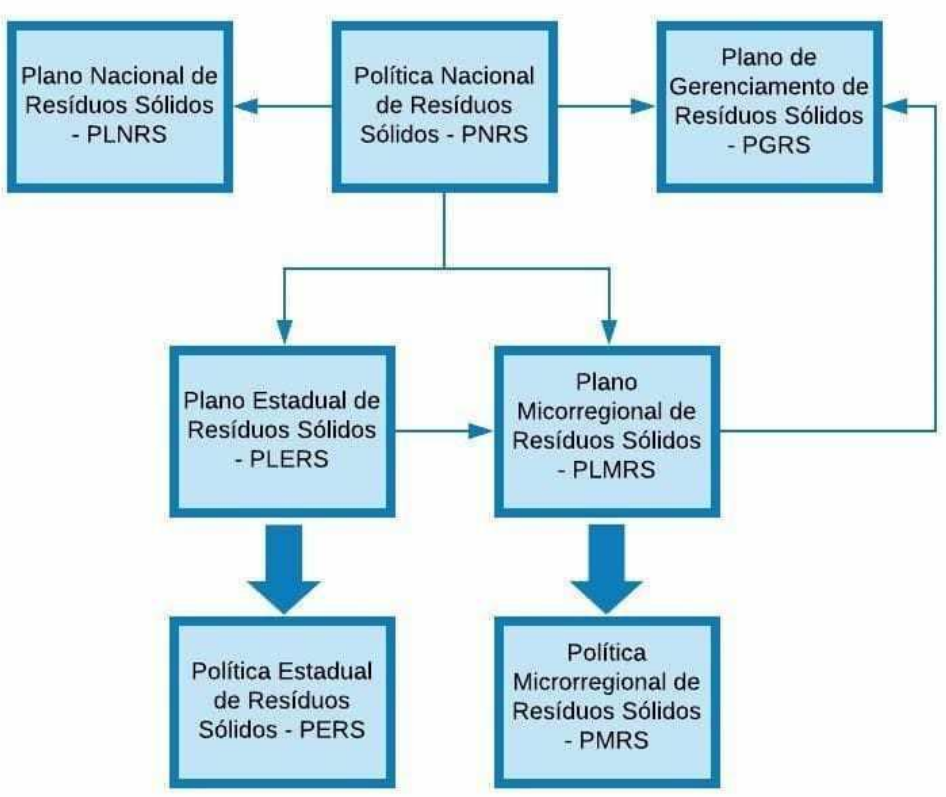

Fonte: Autoria própria com adaptação a partir da Lei 12.305/10 (PNRS).

Disponível em: https://www.nucleodoconhecimento.com.br/engenharia-ambiental/implementacaode-um-biodigestor 
Essa hierarquia é composta por um sistema do qual, a Lei 12.305/10 criada pelo Ministério do Meio Ambiente do Brasil (MMA), impôs sobre obrigação a criação do PLNRS que realiza o primeiro diagnóstico do país, que servirá de base para a elaboração do PLERS e do PLMRS. O PLERS realiza uma análise de todo o estado e cria algumas regulamentações, das quais o PLMRS deve obedecer a fim de definir o PGRS a partir da publicação de um termo de referência que explica para a empresa, seja ela de direito público ou privado, o que é que se precisa levar em consideração para se elaborar um PGRS. Em seguida, com o acúmulo de experiências a partir do PLERS e do PLMRS, será possível criar respectivamente a PERS e a PMRS que definirá por exemplo, a proibição de certos tipos de gases, além da regulamentação de determinados setores ou microssetores. É possível que os municípios de forma individual, elaborem seu próprio plano e política para os resíduos sólidos, sem a necessidades de estarem sujeitos a um PLMRS (ENERGIA E MEIO AMBIENTE, 2015, 4m30s-11m00s).

\subsection{ESTUDO GRAVIMÉTRICO EM SÃO FRANCISCO DE SALES/MG E NO BRASIL}

Com a devida aprovação da PNRS descrita na Lei 12.305/10 e do Decreto 7.404/10, que diz respeito a execução desta Lei, ambos coordenados pelo MMA, o PLNRS realizou um diagnóstico no país referente a dados de composição gravimétrica média do Brasil, provenientes da média de 93 estudos de caracterização físicas realizadas entre 1995 e 2008. A Tabela 02 apresenta a composição gravimétrica média dos RSU no Brasil, considerando como base a quantidade destes resíduos coletados no ano de 2008. 
Tabela 02: Estimativa da composição gravimétrica dos RSU coletados no Brasil em 2008

\begin{tabular}{lcc}
\hline Resíduos & Participação (\%) & Quantidade (t/dia) \\
Material reciclável & $\mathbf{3 1 , 9}$ & $\mathbf{5 8 . 5 2 7 , 4 0}$ \\
$\quad$ Metais & 2,9 & $5.293,50$ \\
Aço & 2,3 & $4.213,70$ \\
Alumínio & 0,6 & $1.079,90$ \\
$\quad$ Papel, papelão e tetrapak & 13,1 & $23.997,40$ \\
$\quad$ Plástico total & 13,5 & $24.847,90$ \\
$\quad$ Plástico filme & 8,9 & $16.399,60$ \\
$\quad$ Plástico rígido & 4,6 & $8.448,30$ \\
$\quad$ Vidro & 2,4 & $4.388,60$ \\
Matéria orgânica & $\mathbf{5 1 , 4}$ & $\mathbf{9 4 . 3 3 5 , 1 0}$ \\
Outros & $\mathbf{1 6 , 7}$ & $\mathbf{3 0 . 6 1 8 , 9 0}$ \\
Total & 100,0 & $183.481,50$ \\
\hline
\end{tabular}

Fonte: Plano Nacional dos Resíduos Sólidos, 2012, p.10.

Podemos definir então que cerca de $51,4 \%$ dos RSU gerados no Brasil se tratam de matéria orgânica, margem esta que utilizaremos como referência para obter uma produção aproximada de RSO gerados pelos 14 municípios do PLMRS. Também realizaremos um estudo gravimétrico dos RSU gerados no município de São Francisco de Sales/MG, utilizando o método de quarteamento.

De acordo com a NBR 10007:2004, o processo de quarteamento se trata de uma análise a partir de uma amostra pré-homogeneizada de RSU, da qual se divide em quatro partes iguais, e dessas partes, tomasse duas opostas entre si para obter uma nova amostra, descartando as outras partes restantes. As duas partes que não foram descartadas são misturadas, repetindo-se o processo de divisão com essa mistura até que se obtenha o volume de análise desejado.

Com base neste método de gravimetria, realizaremos o processo de triagem manual destes resíduos conforme suas características, obtendo-se o percentual de cada material em relação ao volume de análise, podendo por fim, determinar a proporção de RSO contido nos RSU, neste caso, para a cidade de São Francisco de Sales. 


\subsection{INVESTIMENTO DE BIODIGESTOR COM TECNOLOGIA ALEMÃ}

O Portal Resíduos Sólidos publicou no ano de 2013 em seu site, uma matéria sobre o biodigestor da empresa Refood construído na cidade de Marl, na Alemanha, descrevendo como foi realizada a sua implantação, o plano para a forma de coleta seletiva local dos resíduos, o processo de triagem e gravimetria dos RSU, o processamento dos RSO no biodigestor, e o seu custo de implantação. Na Tabela 3, veremos o valor deste investimento.

Tabela 3: Investimento para o Biodigestor na cidade de Marl na Alemanha em 2009

\begin{tabular}{|l|c|c|c|}
\hline \multicolumn{1}{|c|}{ REFERÊNCIA } & $\begin{array}{c}\text { PROCESSAMENTO } \\
\text { (T/dia) }\end{array}$ & $\begin{array}{c}\text { POTÊNCIA } \\
\text { ELÉTRICA (MW) }\end{array}$ & $\begin{array}{c}\text { INVESTIMENTO } \\
\text { ESTIMADO (R\$) }\end{array}$ \\
\hline 01 Biodigestor & 300 & 3 & $60.000 .000,00$ \\
\hline
\end{tabular}

Fonte: Autoria própria com dados retirados do site Portal Resíduos Sólidos, 2013.

Com base nesses valores, e com a proporção gerada de RSO pelos 14 municípios pertencentes ao PLMRS proposto, poderemos estimar o custo de um investimento para a implantação do biodigestor com esta mesma tecnologia.

\section{RESULTADOS E DISCUSSÕES}

Conforme as Figuras 06 e 07 abaixo, no dia 13 de julho de 2019 foi realizado o processo de gravimetria pelo método de quarteamento, no aterro sanitário da cidade de São Francisco de Sales/MG, com o auxílio de colaboradores locais. Foram utilizadas luvas e máscaras como equipamentos de segurança, uma retroescavadeira para homogeneização dos resíduos, pás, enxadas, ancinhos e tambores para caracterização dos resíduos. 


\section{MULTIDISCIPLINARY SCIENTIFIC JOURNAL

Figura 06: Processo de quarteamento.

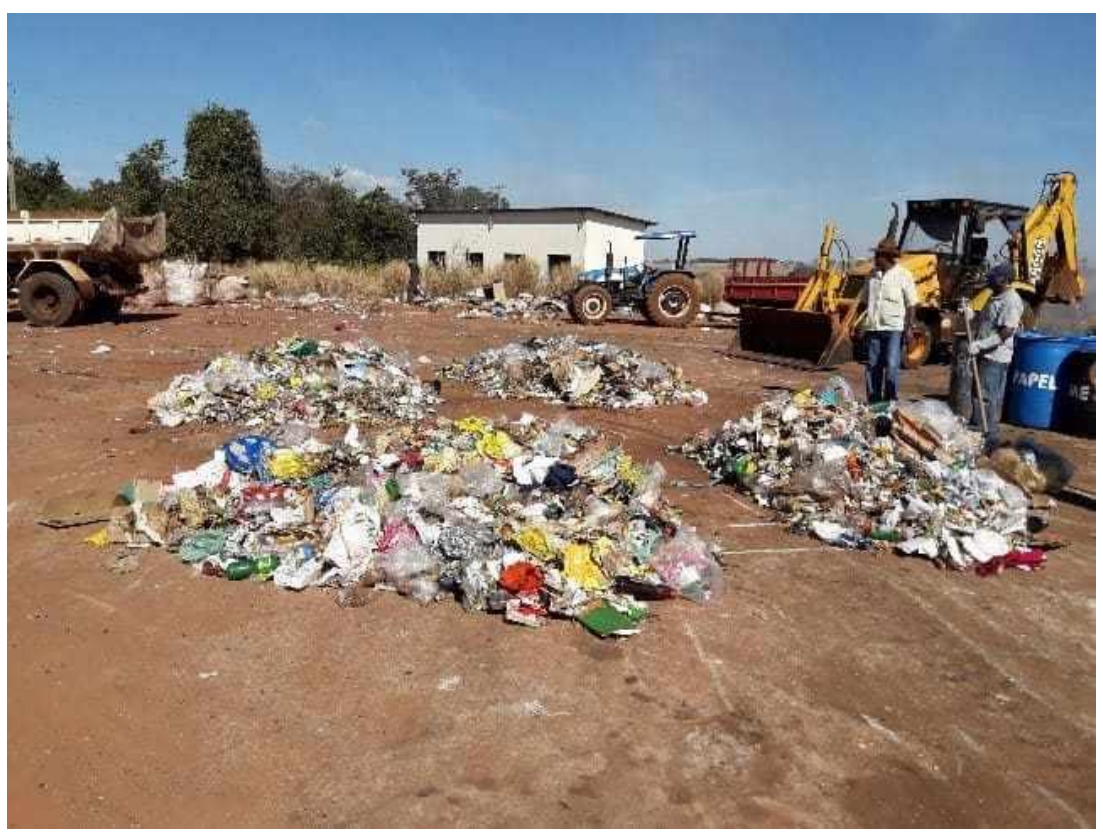

Fonte: Autoria própria.

Figura 07: Classificação dos tipos de resíduos.

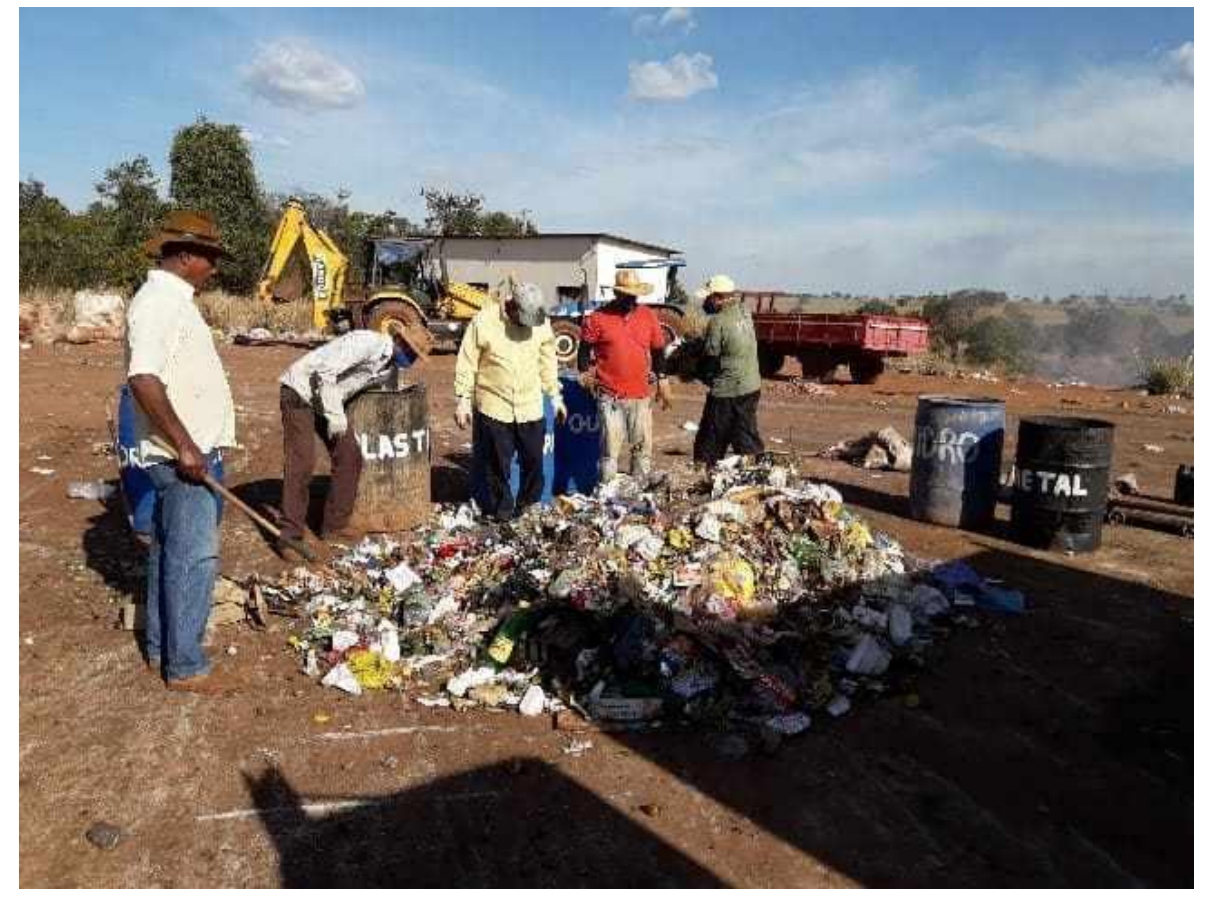

Fonte: Autoria própria.

RC: 42322

Disponível em: https://www.nucleodoconhecimento.com.br/engenharia-ambiental/implementacaode-um-biodigestor 
Logo, ao se obter a quantidade desejada de resíduos com massa total de $375 \mathrm{~kg}$, separamos cada material com sua devida caracterização sendo plástico, papel, vidro, metal, orgânico e outros, conforme o Gráfico 01 abaixo:

Gráfico 01: Gravimetria dos RSU para São Francisco de Sales/MG

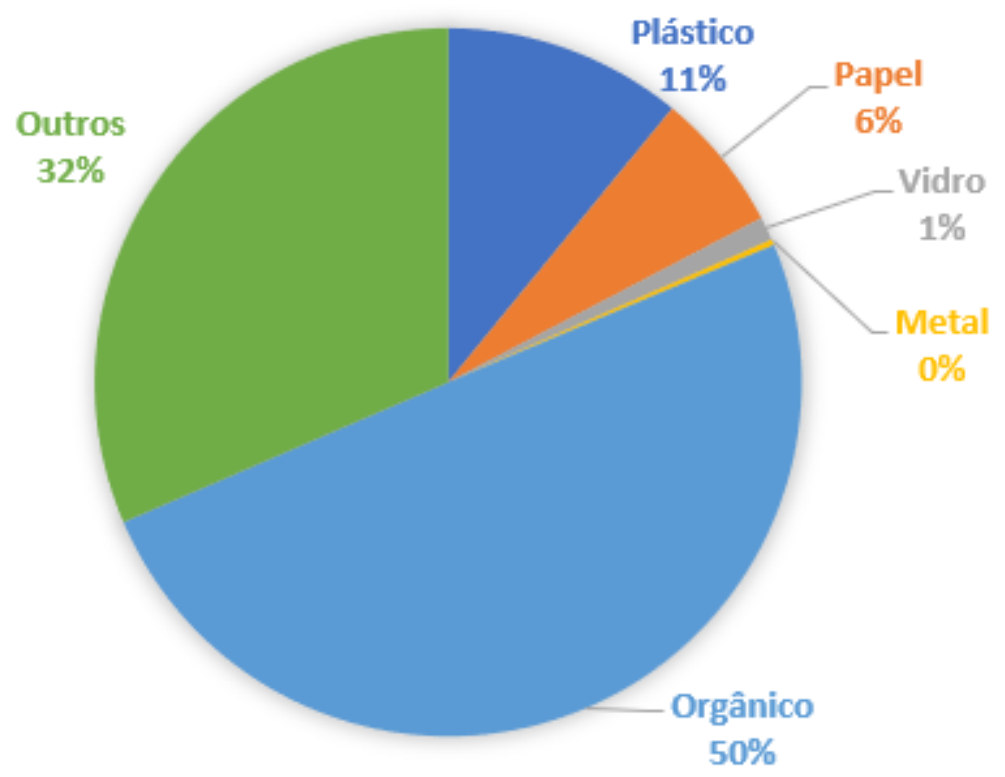

Fonte: Autoria própria.

Podemos notar que $50 \%$ dos RSU gerados neste dia são de origem orgânica. Ao se comparar com a estimativa de $51,4 \%$ dos RSO produzidos no Brasil em geral, conforme a Tabela 02 fornecida pelo PLNRS, notamos que não há muita variação deste percentual.

Com base nos dados de produção de RSU no Brasil fornecida pela ABRELPE, realizamos um estudo dos últimos 10 anos registrados, para se obter uma margem de percentual produtivo, e estipular esta produção para os anos de 2018 e 2019 não registrados, conforme a Tabela 04. Com essas informações, obtivemos uma média de 0,41\% de acréscimo no índice de RSU gerados ao passar dos anos, onde para o ano de 2019, estimados uma produção de 1,227 kg/dia por cada brasileiro, de acordo com a Tabela 05. 
Tabela 04: Estudo de RSU gerados com registro nos últimos 10 anos no Brasil

\begin{tabular}{|c|c|c|}
\hline \multicolumn{3}{|c|}{ PANORAMAS DA ABRELPE } \\
\hline ANO & $\begin{array}{c}\text { ÍNDICE DE RSU GERADO } \\
\text { PER CAPITA } \\
\text { (kg / hab. / dia) }\end{array}$ & $\begin{array}{c}\text { PERCENTUAL } \\
\text { DE PRODUÇÃO } \\
(\%)\end{array}$ \\
\hline 2007 & 1,177 & - \\
\hline 2008 & 1,129 & $-4,08$ \\
\hline 2009 & 1,204 & 6,64 \\
\hline 2010 & 1,234 & 2,49 \\
\hline 2011 & 1,293 & 4,78 \\
\hline 2012 & 1,295 & 0,15 \\
\hline 2013 & 1,209 & $-6,64$ \\
\hline 2014 & 1,239 & 2,48 \\
\hline 2015 & 1,252 & 1,05 \\
\hline 2016 & 1,213 & $-3,12$ \\
\hline 2017 & 1,217 & 0,33 \\
\hline & & \\
\hline
\end{tabular}

Fonte: Autoria própria com dados fornecidos pela ABRELPE, 2019.

Tabela 05: Estimativa para o índice de RSU gerado para o panorama da ABRELPE em 2019

\begin{tabular}{|c|c|c|}
\hline \multicolumn{3}{|c|}{ ESTIMATIVA PARA PANORAMAS DA ABRELPE } \\
\hline ANO & $\begin{array}{c}\text { ÍNDICE DE RSU GERADO } \\
\text { PER CAPITA } \\
(\mathrm{kg} / \text { hab. / dia) }\end{array}$ & $\begin{array}{c}\text { ACRÉSCIMO NO } \\
\text { PERCENTUAL DE PRODUÇ̃̃o } \\
(\%)\end{array}$ \\
\hline 2018 & 1,222 & 0,41 \\
\hline 2019 & 1,227 & 0 \\
\hline
\end{tabular}

Fonte: Autoria própria.

Em seguida, com base nos dados fornecido pelo IBGE para a população estimada dos municípios pertencentes ao PLNRS, e do índice de RSU gerado em 2019 da Tabela 05, obtivemos a quantidade de RSU gerado para cada município, conforme a Tabela 06. Em função do percentual de $51,4 \%$ de RSO gerado no Brasil fornecido 
pelo PLNRS na Tabela 02, obtivemos uma estimativa de mais de $215 \mathrm{~T} /$ dia de RSO gerados pelos 14 municípios do PLMRS proposto, de acordo com a Tabela 07. Lembrando que se trata de uma estimativa, do qual para o dimensionamento final adequado do biodigestor, seria necessário um diagnóstico preciso da produção de RSO para cada município, como por exemplo uma análise de gravimetria anual.

Tabela 06: Quantidade estimada de RSU produzidos para cada município do PLMRS.

\begin{tabular}{|c|l|c|c|}
\hline $\mathbf{N}^{\circ}$ & \multicolumn{1}{|c|}{ CIDADE } & $\begin{array}{c}\text { POPULAÇ̃̃O } \\
\text { ESTIMATIDA PARA } \\
\mathbf{2 0 1 9}\end{array}$ & $\begin{array}{c}\text { QUANTIDADE DE } \\
\text { RSU GERADO } \\
\text { (Kg/dia) }\end{array}$ \\
\hline 01 & São Francisco de Sales & 6.238 & $7.653,98$ \\
\hline 02 & Iturama & 39.263 & $48.175,40$ \\
\hline 03 & Limeira do Oeste & 7.536 & $9.246,61$ \\
\hline 04 & Carneirinho & 10.027 & $12.303,05$ \\
\hline 05 & União de Minas & 4.304 & $5.280,97$ \\
\hline 06 & Itapagipe & 15.243 & $18.703,04$ \\
\hline 07 & Fronteira & 18.103 & $22.212,24$ \\
\hline 08 & Frutal & 59.496 & $73.001,13$ \\
\hline 09 & Comendador Gomes & 3.111 & $3.817,17$ \\
\hline 10 & Prata & 27.856 & $34.179,10$ \\
\hline 11 & Campina Verde & 19.745 & $24.226,96$ \\
\hline 12 & Ituiutaba & 104.671 & $128.430,51$ \\
\hline 13 & Gurinhatã & 5.639 & $6.919,01$ \\
\hline 14 & Santa Vitória & 19.742 & $24.223,28$ \\
\hline & TOTAL $=$ & 340.974 & $418.372,46$ \\
\hline
\end{tabular}

Fonte: Autoria própria com dados fornecidos pelo IBGE, 2019. 
Tabela 07: Quantidade estimada de RSO produzidos para cada município do PLMRS.

\begin{tabular}{|c|c|c|c|c|}
\hline $\begin{array}{c}\text { POPULAÇÃO } \\
\text { ESTIMADA } \\
\text { TOTAL PARA } \\
\mathbf{2 0 1 9}\end{array}$ & $\begin{array}{c}\text { ÍNDICE DE } \\
\text { RSU GERADO } \\
\text { PER CAPITA } \\
\text { (kg / hab. / dia) }\end{array}$ & $\begin{array}{c}\text { QUANTIDADE } \\
\text { DE RSU } \\
\text { GERADO } \\
\text { (Kg/dia) }\end{array}$ & $\begin{array}{c}\text { MATÉRIA } \\
\text { ORGÂNICA }\end{array}$ & $\begin{array}{c}\text { QUANTIDADE } \\
\text { DE RSO } \\
\text { GERADO } \\
\text { (Kg/dia) }\end{array}$ \\
\hline 340.974 & 1,227 & $418.372,46$ & 51,4 & $215.043,45$ \\
\hline
\end{tabular}

Fonte: Autoria própria.

Como apresentado na Tabela 08 abaixo, com base nos dados da Tabela 03 que descreve o investimento para o Biodigestor na cidade de Marl, foi possível estimar um possível custo de quase $R \$ 44,01$ milhões, implementando um Biodigestor com potência de 2,15 MW para o PLMRS, caso venha a processar $100 \%$ dos RSO gerados pelos municípios com a mesma tecnologia alemã.

Tabela 08: Investimento estimado para implantação do Biodigestor com tecnologia alemã para o PLMRS

\begin{tabular}{|l|c|c|c|}
\hline REFERÊNCIA & $\begin{array}{c}\text { PROCESSAMENTO } \\
\text { (T/dia) }\end{array}$ & $\begin{array}{c}\text { POTÊNCIA } \\
\text { ELÉTRICA } \\
\text { (MW) }\end{array}$ & $\begin{array}{c}\text { INVESTIMENTO } \\
\text { ESTIMADO (R\$) }\end{array}$ \\
\hline 01 Biodigestor & 215,04 & 2,15 & $43.008 .689,18$ \\
\hline
\end{tabular}

Fonte: Autoria própria.

\section{CONCLUSÃO}

A escolha de um biodigestor ideal como solução para tratamento de RSO, depende da eficiência do diagnóstico de um plano de negócios. Este plano, realiza um levantamento de dados locais dos municípios que venham a adequar essa tecnologia, levando em consideração o preço da energia local, a aceitação do biofertilizante pelo setor de agricultura como adubo orgânico, o preço local do metano e do crédito de gás carbônico, a logística dos tipos de RSO a serem tratados, a política local, além de outros fatores que venham influenciar diretamente no planejamento e na definição final de qual tecnologia venha a se adotar.

Disponível em: https://www.nucleodoconhecimento.com.br/engenharia-ambiental/implementacao- 
Ao final deste processo de gestão e gerenciamento, com o acúmulo de dados, experiências e soluções a partir de diagnósticos a nível estadual e microrregional, essa forma de tratamento dos RSO irá contribuir para um desenvolvimento sustentável dos municípios pertencentes ao PLMRS, promovendo ao Brasil a seguir o mesmo caminho de países desenvolvidos.

A utilização de outros métodos para tratamentos dos RSO pode ser implementada ao sistema, como usinas de compostagem, vermicomposteira, ou até mesmo biodigestores com tecnologias individuais diferentes ou associadas, sempre com o intuito de atender aos quesitos descritos pela PNRS e do plano de negócios realizado, visando sua viabilidade econômica e contribuição para com o meio ambiente.

\section{REFERÊNCIAS}

ABNT. NBR 10004 - Resíduos sólidos - Classificação - Rio de Janeiro, RJ: ABNT, 2004.

ABNT. NBR 10007 - Amostragem de resíduos sólidos - Rio de Janeiro, RJ: ABNT, 2004.

ABRELPE - ASSOCIAÇÃO BRASILEIRA DE EMPRESAS DE LIMPEZA PÚBLICA E RESÍDUOS ESPECIAIS. Panoramas dos resíduos sólidos no Brasil. Disponível em: $<$ http://abrelpe.org.br/panorama/>. Acesso em: 28 out. 2019.

ALMEIDA, Ronise Nascimento de, et al. A problemática dos resíduos sólidos urbanos - Revista Interfaces Científicas. v.2, n.1. 2013. Disponível em: $<$ https://periodicos.set.edu.br/index.php/saude/article/viewFile/842/501>. Acesso em: 09 out 2019.

Biodigestor de Resíduos Sólidos orgânicos municipais de Marl na Alemanha. Portal Resíduos Sólidos, 26 de jul. de 2013. Disponível em: $<$ https://portalresiduossolidos.com/biodigestor-de-residuos-solidos-organicosmunicipais-de-marl-na-alemanha/>. Acesso em: 28 out. 2019. 
BRASIL. Decreto № 7.404, de 23 de dezembro de 2010. Regulamenta a Lei no 12.305, de 2 de agosto de 2010, que institui a Política Nacional de Resíduos Sólidos, cria o Comitê Interministerial da Política Nacional de Resíduos Sólidos e o Comitê Orientador para a Implantação dos Sistemas de Logística Reversa, e dá outras providências - Brasília, DF, 2010. Disponível em: <http://www.planalto.gov.br/ccivil_03/_Ato2007-2010/2010/Decreto/D7404.htm>. Acesso em: 27 out. 2019.

BRASIL, Lei № 12.305, de 2 de agosto de 2010. Institui a Política Nacional de Resíduos Sólidos; altera a Lei ํํ 9.605, de 12 de fevereiro de 1998; e dá outras providências - Brasília, DF, 2010. Disponível em: $<$ http://www.planalto.gov.br/ccivil_03/_ato2007-2010/2010/lei//12305.htm>. Acesso em: 27 out. 2019.

BRASIL. Plano Nacional de Resíduos Sólidos Brasília - Brasília, DF, 2012. Disponível em

<https://sinir.gov.br/images/sinir/Arquivos_diversos_do_portal/PNRS_Revisao_Decre to_280812.pdf $>$. Acesso em: 27 out. 2019.

BRASIL, Projeto de Lei № 2.289/15. Prorroga o prazo para a disposição final ambientalmente adequada dos rejeitos de que trata o art. 54 da Lei no 12.305, de 2 de agosto de 2010 - Brasília, DF, 2015. Disponível em: <https://www.camara.leg.br/proposicoesWeb/prop_mostrarintegra?codteor $=1417642$ \&filename=SBT+2+CMADS+\%3D\%3E+PL+2289/2015>. Acesso em: 27 out. 2019.

COLOMBAROLI, Tulio Stefani. Análise técnica, econômica e ecológica do uso de biogás em célula a combustível de óxido sólido (SOFC) - Guaratinguetá, SP: UNESP, 2015.

em: $<$ https://repositorio.unesp.br/bitstream/handle/11449/131877/000851931.pdf?sequen $\mathrm{ce}=1$ \&isAllowed=y>. Acesso em: 18 out. 2019.

DEUS, Rafael Mattos, et al. Resíduos sólidos no Brasil: Contexto, lacunas e tendências - Rio de Janeiro, RJ: v.20. Revista Engenharia Sanitária Ambiental, 2015. 
Disponível em: <http://www.scielo.br/pdf/esa/v20n4/1413-4152-esa-20-0400685.pdf>. Acesso em: 09 out. 2019

Funcionamento de um biodigestor alemão - Nível básico - Gleysson. Youtube. 25 nov. 2012.

Disponível

em: <https://www.youtube.com/watch?v=ezH2XrEVTG0\&feature=youtu.be\&t=136>. Acesso em: 27 out. 2019.

GOUVEIA, Nelson. Resíduos sólidos urbanos: impactos socioambientais perspectivas de manejo sustentável com inclusão social - Revista Ciência e Saúde Coletiva, v.17, n.6, 2012. Disponível em: <http://www.scielosp.org/pdf/csc/v17n6/v17n6a14.pdf>. Acesso em 10 out. 2019.

IBGE - INSTITUTO BRASILEIRO DE GEOGRAFIA E ESTATÍSTICA.Malha municipal digital do estado de Minas Gerais - 2018. Disponível em <ftp://geoftp.ibge.gov.br/organizacao_do_territorio/malhas_territoriais/malhas_munici pais/municipio_2018/UFs/MG/mg_municipios.zip>. Acesso em: 28 out. 2019.

IBGE - INSTITUTO BRASILEIRO DE GEOGRAFIA E ESTATÍSTICA. Resultado dos Dados Preliminares do Censo 2010 e estimativa para 2019. Disponível em: <www.ibge.gov.br/cidade@>. Acesso em: 28 out. 2019.

LEI 12.305/2010 e os Planos de Resíduos Sólidos. Energia e Meio Ambiente. Youtube. 29 jan. de 2015. Disponível em: https://www.youtube.com/watch?v=XYF7cZW21sk> Acesso em: 27 out. 2019.

LOMASSO, Alexandre Lourenço, et al. Benefícios e desafios na implementação da reciclagem: Um estudo de caso no centro mineiro de referência em resíduos (CMRR) - Promove, MG: v.3. Ed. Pensar Gestão e Administração, 2015. disponível em: $<$ http://revistapensar.com.br/administracao/pasta_upload/artigos/a104.pdf>. Acesso em: 04 out. 2019. 
VILELA, Breno Silva, et al. A destinação dos resíduos sólidos em llicínea (MG) e proposta de construção de uma vermicomposteira caseira - Poços de Caldas, MG: XII Congresso Nacional de Meio Ambiente de Poços de Caldas, 2015. Disponível em: <http://www.meioambientepocos.com.br/anais/289.\%20A\%20DESTINA\%C3\%87\%C 3\%830\%20DOS\%20RES\%C3\%8DDUOS\%20S\%C3\%93LIDOS\%20URBANOS\%20 EM\%20ILIC\%C3\%8DNEA\%20(MG)\%20E\%20PROPOSTA\%20DE\%20CONSTRU\% C3\%87\%C3\%830\%20DE\%20UMA\%20VERMICOMPOSTEIRA\%20CASEIRA.doc>. Acesso em: 25 set. 2019.

MOTA, José Carlos, et al. Características e impactos ambientais causados pelos resíduos sólidos: uma visão Conceitual - Campina Grande, PB: I Congresso Internacional de Meio Ambiente Subterrâneo, 2009. Disponível em: $<$ https://aguassubterraneas.abas.org/asubterraneas/article/download/21942/14313.p df>. Acesso em: 18 out. 2019.

O TAMANHO DO MERCADO DE BIODIGESTORES NO BRASIL - Energia e Meio Ambiente. Youtube. 26 ago. 2014. Disponível em: <https://www.youtube.com/watch?v=aGWsFYZHZWQ>. Acesso em: 27 out. 2019.

RESÍDUOS SÓLIDOS - Biodigestor - princípio de funcionamento, classificação e viabilidade econômica - Gleysson. Youtube. 31 maio 2013. Disponível em: <https://www.youtube.com/watch?v=ZsdWeC9QMq8>. Acesso em: 27 out. 2019.

ROCHA, Camila Marçal da. Proposta de implantação de um biodigestor anaeróbio de resíduos alimentares - Universidade Federal de Juiz de Fora, Juiz de Fora, MG, 2016. Disponível em: <http://www.ufj.br/engsanitariaeambiental/files/2014/02/TCC-camilafinal-pdf.pdf>. Acesso em: 27 out. 2019.

\section{UBERLÂNDIA É A SEGUNDA CIDADE DE MINAS E A QUINTA DO PAÍS A CONTAR} COM SISTEMA biogás - Odelmo Leão, Uberlândia, MG, 15 de junho de 2012. Disponível em: <http://odelmoleao.com.br/uberlandia-e-a-segunda-cidade-de-minase-a-quinta-do-pais-a-contar-com-sistema-biogas/>. Acesso em: 27 out. 2019. 


\section{ANEXO}

\section{LISTA DE ABREVIATURAS}

ABRELPE - Associação Brasileira de Empresas de Limpeza Pública e Resíduos Especiais

CEMIG - Companhia Energética do Estado de Minas Gerais

CETESB - Companhia de Tecnologia de Saneamento Ambiental

IBGE - Instituto Brasileiro de Geografia e Estatística

MMA - Ministério do Meio Ambiente do Brasil

PERS - Política Estadual de Resíduos Sólidos

PGRS - Plano de Gerenciamento de Resíduos Sólidos

PLERS - Plano Estadual de Resíduos Sólidos

PLMRS - Plano Microrregional de Resíduos Sólidos

PLNRS - Plano Nacional de Resíduos Sólidos

PMRS - Política Microrregional de Resíduos Sólidos

PNRS - Política Nacional de Resíduos Sólidos

RSO - Resíduos Sólidos Orgânicos

RSU - Resíduos Sólidos Urbanos

SECIMA - Secretaria de Meio Ambiente, Recursos Hídricos, Infraestrutura, Cidades e assuntos Metropolitanos 
SEMAD - Secretaria Estadual de Meio Ambiente e Desenvolvimento Sustentável

Enviado: Novembro, 2019.

Aprovado: Dezembro, 2019. 